\title{
Variants in the APOB gene was associated with Ischemic Stroke susceptibility in Chinese Han male population
}

\author{
Feng Zhou ${ }^{1}$, Tie Guo ${ }^{1}$, Lv Zhou ${ }^{1}$, Yanhui Zhou ${ }^{1}$ and Dan Yu ${ }^{1}$ \\ ${ }^{1}$ Department of Neurology, Affiliated Haikou Hospital at Xiangya Medical College, Central South University, Haikou 570208, \\ Hainan, China \\ Correspondence to: Dan Yu, email: danjasaon@qq.com \\ Yanhui Zhou, email: yhzhou81@yeah.net \\ Keywords: Ischemic Stroke; APOB; gene polymorphism; massARRAY \\ Received: June 20,2017 Accepted: September 05, 2017 Published: December 18, 2017 \\ Copyright: Zhou et al. This is an open-access article distributed under the terms of the Creative Commons Attribution License 3.0 \\ (CC BY 3.0), which permits unrestricted use, distribution, and reproduction in any medium, provided the original author and source \\ are credited.
}

\section{ABSTRACT}

Background: Stroke is an extremely complicated disease caused by multiple factors. Epidemiological studies have shown that genetic factors contribute to the pathogenesis of stroke. There is still little research on the effect of $A$ poB gene on stroke in Chinese Han population. The purpose of our research was to explore the effect of $A$ poB gene polymorphism on the genetic susceptibility to Ischemic Stroke in Chinese Han male population.

Materials and methods: 7 polymorphisms in $A p o B$ gene were selected and genotyped using Sequenom MassARRAY in 325 ischemic stroke male patients and 399 healthy male controls in Chinese Han population. The association between $A$ poB gene and genetic susceptibility to Ischemic Stroke was performed by the $X^{2}$ test, genetic model analysis and haplotype analysis.

Results: In the allele model, ApoB rs1042034 "T" allele and rs673548 "G" allele increased the risk of the Ischemic Stroke (rs1042034: OR=1.29, 95\%CI: 1.02-1.63, $\mathrm{p}=0.030$; rs673548: $\mathrm{OR}=1.28,95 \% \mathrm{CI}$ : 1.02-1.62, $\mathrm{p}=0.034$ ). Logistic regression analysis found that $A$ POB rs1042034 and rs673548 increased the risk of Ischemic Stroke in the log-additive model, the odds of having Ischemic Stroke would be 1.28fold and 1.27-fold with the variant allele, respectively. We also found that the risk of individuals carrying the ApoB rs693 "AA-AG" genotype had Ischemic Stroke risk of 1.52-fold of carrying "GG" genotype in the dominant model. The haplotype analysis shown that "TAG" haplotype raised the risk of Ischemic Stroke (OR=1.52, 95\%CI: 1.02-2.27, $p=0.0042$ ).

Conclusion: The polymorphisms of the $A p o B$ gene may affect Ischemic Stroke occurrence.

\section{INTRODUCTION}

Strokes are one of the three most common causes of death and the major cause of adult chronic disability. A stroke is a sudden onset of cerebral blood circulation disruption. Once a stroke has occurred, most affected individuals suffer from disability, cognitive dysfunction and other complications and have a higher risk of death. About 15 million people suffer from strokes for the first time each year, of which $1 / 3$, or about 6.6 million, result in death [1]. Risk factors for coronary artery disease (CAD) and ischemic stroke include hypertension, diabetes, dyslipidemia, and metabolic syndrome [2]. Dyslipidemia, i.e., elevated levels of total cholesterol, triglycerides, lowdensity lipoprotein and lipoprotein, and a decrease in HDL levels are risk factors for stroke $[3,4]$. At present, more and more attention has been paid to the genetic factors of Ischemic Stroke.

The $A p o B$ gene is located on the short arm of human chromosome 2 , with a length of $43 \mathrm{~kb}$. The expression 
Table 1: Basic SNPs in APOB gene summary of all study participants

\begin{tabular}{lcccccccccc}
\hline SNP rs\# & Chr & Position & Band & $\begin{array}{c}\text { Alleles } \\
\text { A/B }\end{array}$ & Role & $\begin{array}{c}\text { Amino } \\
\text { acid } \\
\text { change }\end{array}$ & $\begin{array}{c}\text { Amino } \\
\text { acid } \\
\text { position }\end{array}$ & H-W $\boldsymbol{p}$ & OR(95\%CI) & $\boldsymbol{p}$ \\
\hline rs1042034 & 2 & 21225281 & $2 \mathrm{p} 24.1$ & $\mathrm{~T} / \mathrm{C}$ & Coding exon & $\mathrm{S} / ?$ & 4338 & 0.3519 & $1.29(1.02-1.63)$ & 0.03 \\
rs1801702 & 2 & 21225485 & $2 \mathrm{p} 24.1$ & $\mathrm{G} / \mathrm{C}$ & Coding exon & $\mathrm{R} / \mathrm{T}$ & 4270 & 1 & $0.92(0.47-1.81)$ & 0.807 \\
rs693 & 2 & 21232195 & $2 \mathrm{p} 24.1$ & $\mathrm{~A} / \mathrm{G}$ & Coding exon & $\mathrm{T} / ?$ & 2515 & 0.6686 & $1.44(0.97-2.12)$ & 0.069 \\
rs673548 & 2 & 21237544 & $2 \mathrm{p} 24.1$ & $\mathrm{G} / \mathrm{A}$ & $\begin{array}{c}\text { Intron } \\
\text { (boundary) }\end{array}$ & -- & -- & 0.3531 & $1.28(1.02-1.62)$ & 0.034 \\
rs3791981 & 2 & 21245367 & $2 \mathrm{p} 24.1$ & $\mathrm{G} / \mathrm{A}$ & Intron & -- & -- & 1 & $1.09(0.66-1.8)$ & 0.744 \\
rs679899 & 2 & 21250914 & $2 \mathrm{p} 24.1$ & $\mathrm{G} / \mathrm{A}$ & Coding exon & $\mathrm{A} / ?$ & 618 & 0.8514 & $1.22(0.93-1.6)$ & 0.155 \\
rs512535 & 2 & 21267782 & $2 \mathrm{p} 24.1$ & $\mathrm{~T} / \mathrm{C}$ & Promoter & -- & -- & 0.6662 & $1.18(0.92-1.5)$ & 0.192 \\
\hline
\end{tabular}

A/B stands for minor/major alleles on the control sample frequencies.

SNPs are excluded at 5\% HWE $P$ level.

$p<0.05$ indicates statistical significance.

products of $\mathrm{ApoB}$ gene are mainly divided into Apo B100 and Apo B48. Apo B100 is a regulatory factor involved in thrombosis. Apo B48 participates in the synthesis, assembly and secretion of VLDL and participates in the digestion, absorption and transportation of exogenous lipids. One research consisted of 1128 people, and revealed that $A p o B$ rs 1042034 loci was significant associated with plasma cholesterol [5]. Another study found that oxLDL influence the incidence of stroke [6], and rs676210 in $A p o B$ gene associated with oxLDL [7], so rs676210 loci may affect the incidence risk of stroke. Two small case-control studies $[8,9]$ and a small cohort study of patients with Ischemic stroke found that elevated apoB was associated with an increased risk Ischemic stroke [10].

However, there is little research on the relationship between $A p o B$ gene and ischemic stroke in Chinese people. So, the purpose of our research was to explore the effect of $A p o B$ gene polymorphism on the genetic susceptibility to Ischemic Stroke in Chinese Han male population.

\section{RESULTS}

Table 1 shown that 7 SNPs were met HWE. In the allele model, $A p o B$ rs1042034 "T" allele and rs673548 "G" allele increased the risk of the Ischemic Stroke (rs1042034: OR=1.29, 95\%CI: 1.02-1.63, $p=0.030$; rs673548: $\mathrm{OR}=1.28,95 \% \mathrm{CI}: 1.02-1.62, p=0.034)$.

Through the genetic models analyses as shown Table 2, we found that $A p o B$ rs 1042034 and rs673548 increased the risk of Ischemic Stroke under the logadditive model, the odds of having Ischemic Stroke would be 1.28 -fold $(\mathrm{OR}=1.28,95 \% \mathrm{CI}$ : $1.02-1.60, p=0.034)$ and 1.27 -fold ( $\mathrm{OR}=1.27,95 \% \mathrm{CI}$ : $1.01-1.60, p=0.038)$ with the variant allele, respectively. Meanwhile, we also found that the risk of individuals carrying the $A p o B$ rs693 "AA-AG" genotype had Ischemic Stroke risk of 1.52-fold of carrying GG genotype $(\mathrm{OR}=1.52,95 \% \mathrm{CI}: 1.00-2.30, p=0.047)$ under the dominant model.

The linkage disequilibrium degree between two SNP loci was measured by the parameter $D^{\prime}$ and $\mathrm{R}^{2}$, and the haplotype block was divided by D' confidence interval method. Figure 1 shown that rs1042034, rs693, and rs673548 are highly linked, and further haplotype analysis revealed that haplotype "TAG" increased the risk of Ischemic stroke compared the haplotype "CGA" $(\mathrm{OR}=1.52,95 \% \mathrm{CI}: 1.02-2.27, p=0.0042)$ (Table 3$)$.

\section{DISCUSSION}

Some studies found that elevated apoB level added the risk of Ischemic stroke [8-10]. We investigated the effects of $A p o B$ gene on susceptibility to Ischemic stroke in Chinese male population, and found that rs1042034, rs693 and rs673548 in $A p o B$ gene increased the risk of Ischemic stroke in Chinese Han population.

The AP69 gene rs693 loci (C> T, synonymous mutation) is located in exon 26 of the $A p o B$ gene, closely related to blood lipid level. Kathiresan and his colleagues found that the levels of LDL-C and TG of the rs693 T allele carriers were higher than the rs693 C allele carriers [11]. Rodrigues et al. found that rs693 locus $\mathrm{T}$ allele carriers had higher levels of TC and LDL-C by case-control analysis [12]. Boekholdt et al. [13] found that Homozygotes for the XbaI elevated levels of LDL cholesterol (LDL-C) and apoB, but decreased the risk of ischemic heart disease. In our data, rs673548 also showed significant associations with Ischemic Stroke risk, and rs693 and rs673548 have stronger linkage.

We also found that $A p o B$ rs1042034, a missense resulting in Ser4338Asn, increased the risk of Ischemic stroke, the odds of having Ischemic Stroke would be 1.28- 
Table 2: Association of APOB SNPs with Ischemic Stroke risk based on logistical tests

\begin{tabular}{|c|c|c|c|c|c|c|c|c|}
\hline \multirow{2}{*}{ SNP } & \multirow{2}{*}{ Model } & \multirow{2}{*}{ Genotype } & \multirow{2}{*}{ Control } & \multirow{2}{*}{ Case } & \multicolumn{2}{|c|}{ Crude analysis } & \multicolumn{2}{|c|}{ Adjusted analysis } \\
\hline & & & & & OR (95\% CI) & $p$-value & OR $(95 \% \mathrm{CI})$ & $p$-value \\
\hline \multirow[t]{8}{*}{ rs1042034 } & Codominant & $\mathrm{C} / \mathrm{C}$ & $227(56.9 \%)$ & $161(49.5 \%)$ & 1 & 0.11 & 1 & 0.2 \\
\hline & & $\mathrm{T} / \mathrm{C}$ & $143(35.8 \%)$ & $131(40.3 \%)$ & $\begin{array}{c}1.29(0.95- \\
1.76)\end{array}$ & & $1.42(0.96-2.10)$ & \\
\hline & & $\mathrm{T} / \mathrm{T}$ & $29(7.3 \%)$ & $33(10.2 \%)$ & $\begin{array}{c}1.60(0.94- \\
2.75)\end{array}$ & & $1.27(0.64-2.50)$ & \\
\hline & Dominant & $\mathrm{C} / \mathrm{C}$ & $227(56.9 \%)$ & $161(49.5 \%)$ & 1 & 0.048 & 1 & 0.078 \\
\hline & & $\mathrm{T} / \mathrm{C}-\mathrm{T} / \mathrm{T}$ & $172(43.1 \%)$ & $164(50.5 \%)$ & $\begin{array}{c}1.34(1.00- \\
1.80)\end{array}$ & & $1.39(0.96-2.01)$ & \\
\hline & Recessive & $\mathrm{C} / \mathrm{C}-\mathrm{T} / \mathrm{C}$ & $370(92.7 \%)$ & $292(89.8 \%)$ & 1 & 0.17 & 1 & 0.79 \\
\hline & & $\mathrm{T} / \mathrm{T}$ & $29(7.3 \%)$ & $33(10.2 \%)$ & $\begin{array}{c}1.44(0.86- \\
2.43)\end{array}$ & & $1.09(0.56-2.12)$ & \\
\hline & Log-additive & --- & --- & --- & $\begin{array}{c}1.28(1.02- \\
1.60)\end{array}$ & 0.034 & $1.24(0.93-1.65)$ & 0.14 \\
\hline \multirow[t]{8}{*}{ rs693 } & Codominant & $\mathrm{G} / \mathrm{G}$ & $350(87.7 \%)$ & $268(82.5 \%)$ & 1 & 0.11 & 1 & 0.16 \\
\hline & & $\mathrm{G} / \mathrm{A}$ & $47(11.8 \%)$ & $56(17.2 \%)$ & $\begin{array}{c}1.56(1.02- \\
2.37)\end{array}$ & & $1.65(0.98-2.79)$ & \\
\hline & & $\mathrm{A} / \mathrm{A}$ & $2(0.5 \%)$ & $1(0.3 \%)$ & $\begin{array}{c}0.65(0.06- \\
7.24)\end{array}$ & & $\begin{array}{c}0.75(0.04- \\
13.23)\end{array}$ & \\
\hline & Dominant & $\mathrm{G} / \mathrm{G}$ & $350(87.7 \%)$ & $268(82.5 \%)$ & 1 & 0.047 & 1 & 0.068 \\
\hline & & G/A-A/A & $49(12.3 \%)$ & $57(17.5 \%)$ & $\begin{array}{c}1.52(1.00- \\
2.30)\end{array}$ & & $1.62(0.96-2.71)$ & \\
\hline & Recessive & G/G-G/A & $397(99.5 \%)$ & $324(99.7 \%)$ & 1 & 0.68 & 1 & 0.8 \\
\hline & & $\mathrm{A} / \mathrm{A}$ & $2(0.5 \%)$ & $1(0.3 \%)$ & $\begin{array}{c}0.61(0.06- \\
6.78)\end{array}$ & & $\begin{array}{c}0.69(0.04- \\
12.27)\end{array}$ & \\
\hline & Log-additive & --- & --- & --- & $\begin{array}{c}1.45(0.97- \\
2.15)\end{array}$ & 0.067 & $1.53(0.94-2.50)$ & 0.09 \\
\hline \multirow[t]{8}{*}{ rs673548 } & Codominant & $\mathrm{A} / \mathrm{A}$ & $225(56.7 \%)$ & $159(49.2 \%)$ & 1 & 0.11 & 1 & 0.22 \\
\hline & & $\mathrm{A} / \mathrm{G}$ & $143(36 \%)$ & $132(40.9 \%)$ & $\begin{array}{c}1.31(0.96- \\
1.78)\end{array}$ & & $1.41(0.96-2.09)$ & \\
\hline & & $\mathrm{G} / \mathrm{G}$ & $29(7.3 \%)$ & $32(9.9 \%)$ & $\begin{array}{c}1.56(0.91- \\
2.68)\end{array}$ & & $1.23(0.62-2.45)$ & \\
\hline & Dominant & $\mathrm{A} / \mathrm{A}$ & $225(56.7 \%)$ & $159(49.2 \%)$ & 1 & 0.046 & 1 & 0.088 \\
\hline & & A/G-G/G & $172(43.3 \%)$ & $164(50.8 \%)$ & $\begin{array}{c}1.35(1.00- \\
1.81)\end{array}$ & & $1.38(0.95-1.99)$ & \\
\hline & Recessive & $\mathrm{A} / \mathrm{A}-\mathrm{A} / \mathrm{G}$ & $368(92.7 \%)$ & $291(90.1 \%)$ & 1 & 0.21 & 1 & 0.85 \\
\hline & & $\mathrm{G} / \mathrm{G}$ & $29(7.3 \%)$ & $32(9.9 \%)$ & $\begin{array}{c}1.40(0.83- \\
2.36)\end{array}$ & & $1.07(0.55-2.08)$ & \\
\hline & Log-additive & --- & --- & --- & $\begin{array}{c}1.27(1.01- \\
1.60)\end{array}$ & 0.038 & $1.23(0.92-1.63)$ & 0.16 \\
\hline
\end{tabular}

$p<0.05$ indicates statistical significance. 
Table 3: ApoB haplotype frequencies and their association with Ischemic Stroke

\begin{tabular}{|c|c|c|c|c|c|c|}
\hline & \multirow{2}{*}{ Haplotype } & \multirow{2}{*}{ Freq } & \multicolumn{2}{|c|}{ Crude analysis } & \multicolumn{2}{|c|}{ Adjusted analysis } \\
\hline & & & OR $(95 \% \mathrm{CI})$ & $p$-value & OR $(95 \%$ CI $)$ & $p$-value \\
\hline \multirow[t]{3}{*}{$\begin{array}{l}\text { rs1042034/rs693/ } \\
\text { rs673548 }\end{array}$} & CGA & 0.7238 & 1 & & 1 & \\
\hline & TGG & 0.1989 & $1.20(0.93-1.55)$ & 0.16 & $1.13(0.82-1.56)$ & 0.46 \\
\hline & TAG & 0.0753 & $1.52(1.02-2.27)$ & 0.042 & $1.57(0.96-2.58)$ & 0.072 \\
\hline
\end{tabular}

$p<0.05$ indicates statistical significance.

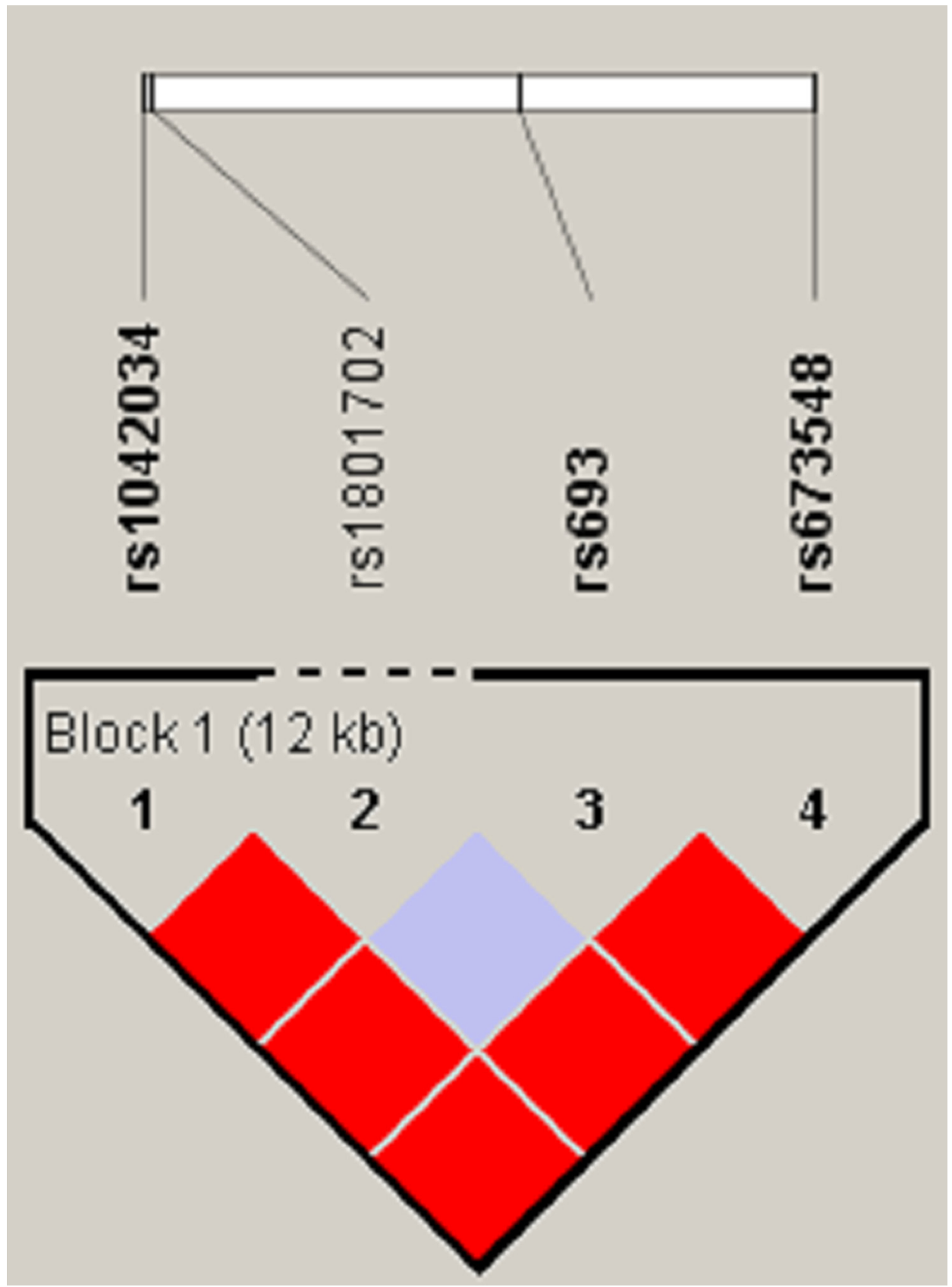

Figure 1: Haplotype block for the SNPs of ApoB. 
fold with the variant allele. In the study of Kim, which including 1128 participants, revealed that $A p o B$ rs 1042034 loci was significant associated with plasma cholesterol [5]. Kulminski AM et al. tracing the cardiovascular disease in the United States found that the rs1042034 "CC" genotype of $A p o B$ gene is related to the increase of serum total cholesterol in young population, but the protective effect on lipid metabolism in elderly people [14]. So, we speculate that $A p o B$ influences the risk of occurrence of Ischemic Stroke by influencing the concentration of lipoprotein.

In conclusion, our study revealed that $A p o B$ rs1042034, rs693 and rs673548 mutation were significantly associations with the hereditary susceptibility of Ischemic stroke. Although sample size is small, our research has certain significance. In the future we will increase the sample size for validation studies.

\section{MATERIALS AND METHODS}

\section{Study participants}

A case-control study involving a Chinese study population of 325 ischemic stroke male patients (age mean: 63.44 year) and 399 healthy male controls (age mean: 47.57 year) was conducted at the Affiliated Haikou Hospital at Xiangya medical college, Central South University. All included patients were diagnosed according to the International Classification of Disease (9th revision, codes 430 to 438) on the basis of history, clinical symptoms, physical examination, and cranial computed tomography (CT) or magnetic resonance imaging (MRI). Patients with hemorrhagic stroke, subarachnoid hemorrhage, transient ischemic attack, traumatic brain injuries, infectious diseases, and tumors were excluded in this study. The controls were recruited from the Physical Examination Department in the same hospital. None of the controls showed evidence of stroke or other neurological diseases. Control participants with tumors, autoimmune diseases, liver ailments, nephrosis, or hematological diseases were excluded.

All of the participants signed an informed consent agreement. The Human Research Committee for Approval of Research Involving Human Subjects, Affiliated Haikou Hospital at Xiangya medical college, Central South University approved the use of human tissue in this study.

\section{SNP selection and genotyping}

We selected seven candidate SNPs of $A p o B$ according to previous published papers which demonstrated association with lipid metabolism abnormality related diseases and minor allele frequencies $>5 \%$ in the HapMap Chinese Han Beijing population. We used the GoldMag-Mini Whole Blood Genomic DNA Purification Kit (GoldMag Co. Ltd. Xi'an City,
China) extracted from whole blood. Using a NanoDrop 2000 (Gene Company Limited) were measured DNA concentrations. We used SequenomMassARRAY Assay Design 3.0 Software to design a Multiplexed SNP MassEXTEND assay [15]. SequenomMassARRAY RS1000 was used for genotyping, and the related data were managed using SequenomTyper 4.0 Software [15, 16]. Laboratory personnel were blinded to the genotyping results of all samples.

\section{Statistical analysis}

Data analysis was performed using Microsoft Excel (Redmond, WA, USA) and SPSS 19.0 statistical package (SPSS, Chicago, IL, USA). All p values were two-sided, and $\mathrm{p}<0.05$ was indicated statistical significance. Each SNP frequency in the control subjects was assessed for departure from Hardy-Weinberg Equilibrium (HWE) using an exact test. We calculated genotype frequencies of cases and controls using a $\chi^{2}$ test [17]. Odds ratios (ORs) and $95 \%$ confidence intervals (CIs) were determined using unconditional logistic regression with adjustment for age and sex [18].

Five genetic models (genotype, dominant, recessive, and additive model) were performed using PLINK software (http://pngu.mgh.harvard.edu/purcell/plink/), to characterize the potential association of each $A p o B$ polymorphism with the risk of esophageal carcinoma. Finally, we used Haploview software package (version 4.2) to evaluate pairwise linkage disequilibrium (LD), haplotype construction, and genetic association at the polymorphic loci $[19,20]$.

\section{ACKNOWLEDGMENTS}

This work is supported by the key scientific and technological project of Hainan Province (No. ZDXM20130066). We are grateful to Dr. Ying Xia and Dr. Tianbo Jin for their advice on experimental design. We are grateful to all the patients and individuals in the study who made this work possible. We would also like to thank the clinicians and hospital staffs who contributed to data collection for this study.

\section{CONFLICTS OF INTEREST}

The authors declare no conflicts of interest.

\section{REFERENCES}

1. Reinhardt E. The atlas of heart disease and stroke. UN Chronicle. 2005; 19:505-505.

2. Fruchart JC, Nierman MC, Stroes ES, Kastelein JJ, Duriez P. New risk factors for atherosclerosis and patient risk assessment. Circulation. 2004; 109:III15-19. 
3. Tanne D, Yaari S, Goldbourt U. High-density lipoprotein cholesterol and risk of ischemic stroke mortality. A 21-year follow-up of 8586 men from the Israeli Ischemic Heart Disease Study. Stroke. 1997; 28:83-87.

4. Soyama Y, Miura K, Morikawa Y, Nishijo M, Nakanishi Y, Naruse Y, Kagamimori S, Nakagawa H, Oyabe S. High-density lipoprotein cholesterol and risk of stroke in Japanese men and women: the Oyabe Study. Stroke. 2003; 34:863-868.

5. Kim DS, Burt AA, Ranchalis JE, Jarvik ER, Rosenthal EA, Hatsukami TS, Furlong CE, Jarvik GP. Novel geneby-environment interactions: APOB and NPC1L1 variants affect the relationship between dietary and total plasma cholesterol. J Lipid Res. 2013; 54:1512-1520.

6. Serebruany V, Sani Y, Eisert C, Schevchuck A, Fong A, Hanley D. Effects of Aggrenox and aspirin on plasma endothelial nitric oxide synthase and oxidised low-density lipoproteins in patients after ischaemic stroke. Thromb Haemost. 2011; 105:81-87.

7. Mäkelä KM, Seppälä I, Hernesniemi JA, Lyytikäinen LP, Oksala N, Kleber ME, Scharnagl H, Grammer TB, Baumert J, Thorand B. Genome-wide association study pinpoints a new functional apolipoprotein $\mathrm{B}$ variant influencing oxidized low-density lipoprotein levels but not cardiovascular events: AtheroRemo Consortium. Circ Cardiovasc Genet. 2013; 6:73-81.

8. Boutron MC, Giroud M, Gras P, Gambert P, Lallemant C, Milan C, Essayagh E, Dumas R. Plasma lipoproteins in cortical infarction versus transient ischaemic attacks: a case control study. J Neurol. 1993; 240:133-138.

9. Giubilei F, D’Antona R, Antonini R, Lenzi GL, Ricci G, Fieschi C. Serum lipoprotein pattern variations in dementia and ischemic stroke. Acta Neurol Scand. 1990; 81:84-86.

10. Simons LA, Simons J, Friedlander Y, McCallum J. Cholesterol and other lipids predict coronary heart disease and ischaemic stroke in the elderly, but only in those below 70 years. Atherosclerosis. 2001; 159:201-208.

11. Kathiresan S, Melander O, Guiducci C, Surti A, Burtt NP, Rieder MJ, Cooper GM, Roos C, Voight BF, Havulinna
AS, Wahlstrand B, Hedner T, Corella D, et al. Six new loci associated with blood low-density lipoprotein cholesterol, high-density lipoprotein cholesterol or triglycerides in humans. Nat Genet. 2008; 40:189-197.

12. Rodrigues AC, Sobrino B, Genvigir FD, Willrich MA, Arazi SS, Dorea EL, Bernik MM, Bertolami M, Faludi AA, Brion MJ. Genetic variants in genes related to lipid metabolism and atherosclerosis, dyslipidemia and atorvastatin response. Clin Chim Acta. 2013; 417:8.

13. Boekholdt SM, Peters RJ, Fountoulaki K, Kastelein JJ, Sijbrands EJ. Molecular variation at the apolipoprotein B gene locus in relation to lipids and cardiovascular disease: a systematic meta-analysis. Hum Genet. 2003; 113:417-425.

14. Kulminski AM, Culminskaya I, Arbeev KG, Ukraintseva SV, Stallard E, Arbeeva L, Yashin AI. The role of lipidrelated genes, aging-related processes, and environment in healthspan. Aging Cell. 2013; 12:237-246.

15. Gabriel S, Ziaugra L, Tabbaa D. SNP genotyping using the Sequenom MassARRAY iPLEX platform. Curr Protoc Hum Genet. 2009; Chapter 2:Unit 2.12.

16. Thomas RK, Baker AC, Debiasi RM, Winckler W, Laframboise T, Lin WM, Wang M, Feng W, Zander T, MacConaill L, Lee JC, Nicoletti R, Hatton C, et al. Highthroughput oncogene mutation profiling in human cancer. Nat Genet. 2007; 39:347-351.

17. Adamec C. [Example of the use of the nonparametric test. Test X2 for comparison of 2 independent examples]. [Article in Czech]. Cesk Zdrav. 1964; 12:613-619.

18. Bland JM, Altman DG. Statistics notes. The odds ratio. BMJ. 2000; 320:1468.

19. Barrett JC, Fry B, Maller J, Daly MJ. Haploview: analysis and visualization of LD and haplotype maps. Bioinformatics. 2005; 21:263-265.

20. Hawley ME, Kidd KK. HAPLO: a program using the EM algorithm to estimate the frequencies of multi-site haplotypes. J Hered. 1995; 86:409-411. 